\title{
A rose in any other shade: Is alpine flower pollinator distribution driven by colour?
}

\author{
Hannah Zurcher, Ming-Dao Chia, Julia Hammer
}

\section{Abstract}

While some plant-pollinator relations are born of scarcity, competition or necessity, the stunning diversity of Australian alpine flora lends itself to rich fields of varied blooms. If there is any plantpollinator selection happening in the Australian Alps, then it is likely due to insect colour preference. Insects often prefer flowers of specific colours, as visual cues provide guidance for resource distribution. Bees generally prefer yellow flowers, flies white flowers and beetles white flowers.

There are more white flowers (53.5 per cent), than yellow (21.3 per cent) in Kosciuszko National Park. Oxylobium ellipticum, the common shaggy-pea, is a yellow flower found near Charlotte Pass. Epacris paludosa, a star-shaped flower, is white and found in a range of alpine areas. Olearia phlogopappa, the dusty daisy-bush, blooms both purple and white and is found over much of Australia.

Alpine insects are more restricted than temperate insects in terms of food sources, due to year-round lack of both animal and plant food sources. In spring, then, when flowers bloom, insects take every opportunity they can to feed. Flies are the most common pollinator in Kosciuszko National Park. Bees are more specialist feeders than beetles and flies. Thus, bees generally prefer flowers with more closed structures. Beetles and flies generally prefer more open-structured flowers. Insect pollinators generally prefer flowers with stronger scent signals, and honey bees have been shown almost never to land on a flower without both a colour and scent stimulus. 
Given that floral feeding is an important part of the life cycles of alpine insects, pollination selection will differ widely between insect species. We hypothesised that pollinator visitation will differ significantly in terms of morphotype and number of pollinators between Australian alpine native species O. ellipticum, E. paludosa and O. phlogopappa.

Despite visible trends towards pollinator selection, no significant difference could be determined overall. Greater time, more varied conditions, surveys of present insect species and control for plant height (e.g. beetles fly less than bees, so may pollinate yellow plants low to the ground but not higher yellow plants, leading to misleading results) could all refine discussion of alpine plant-pollinator relationships.

\section{Method}

We located a field site in subalpine woodland that contained patches of Oxylobium ellipticum, Epacris paludosa, Olearia phlogopappa, with at least one of each in flower and of a structural density that did not leave the plants obviously abnormally sparse.

We observed all three flower species for at least 10 minutes respectively as a group to identify common morphotypes of pollinators, agreed on a system of labelling and generally assured that variations in observational techniques between individuals were limited.

We collected relevant field data: average wind speed and current temperature using a Kestral at both the beginning and end of each halfhour measuring period.

Over a 30-minute period, observers recorded all flower visitations and feedings to the patch of one of the species studied. Each species of plant was observed by at least one group member between each observing period. Morphotype of pollinator was recorded each time it landed on a flower. Whether it fed on the flower or simply visited was recorded.

Each subsequent half-hour observation period was done in a separate location to any of the previous. Researchers attempted to observe a reasonably equal number of the three different plant species over all of the different observational periods. 
a)

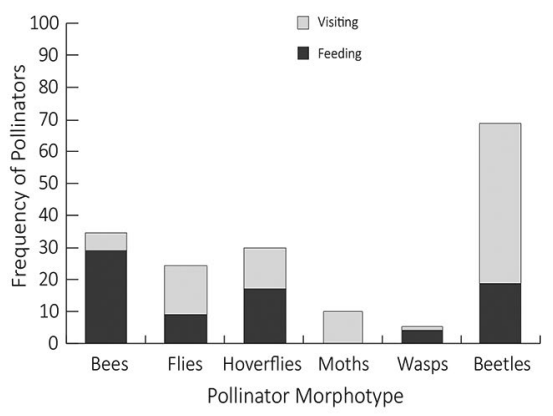

c)

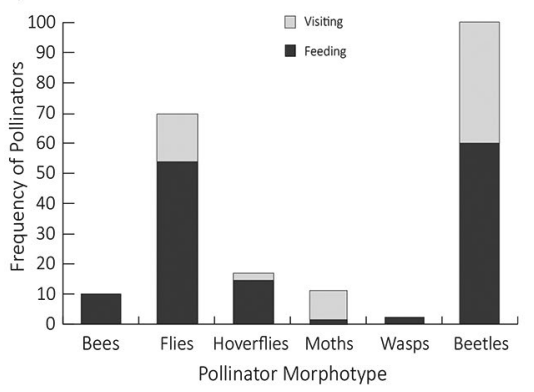

b)

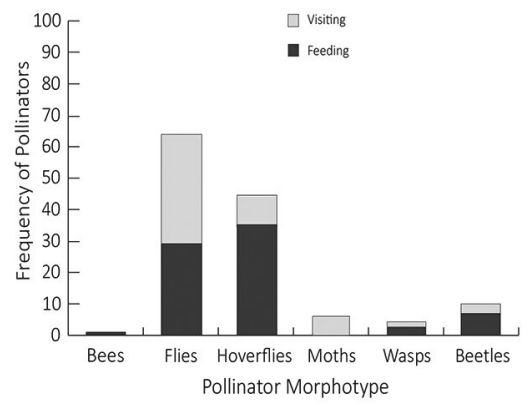

Figure 1: Frequency of pollinator morphotypes on a) Oxylobium ellipticum, b) Olearia phlogopappa, and c) Epacris paludosa. Dark grey bars represent feeding frequency, and light grey bars represent visiting frequency; for example, on 0 . ellipticum 20 beetles fed and 49 beetles visited.

Source: Authors' data.

\section{Results}

Figure 1 compares the frequency of each pollinator morphotype (defined as bees, flies, hoverflies, moths, wasps and beetles) on O. ellipticum, $O$. phlogopappa and E. paludosa. Landing on flowers (visiting) was distinguished from feeding. Figure 2 emphasises pollinator preference for the three flowering plant species. 
RESEARCHING FUNCTIONAL ECOLOGY IN KOSCIUSZKO NATIONAL PARK
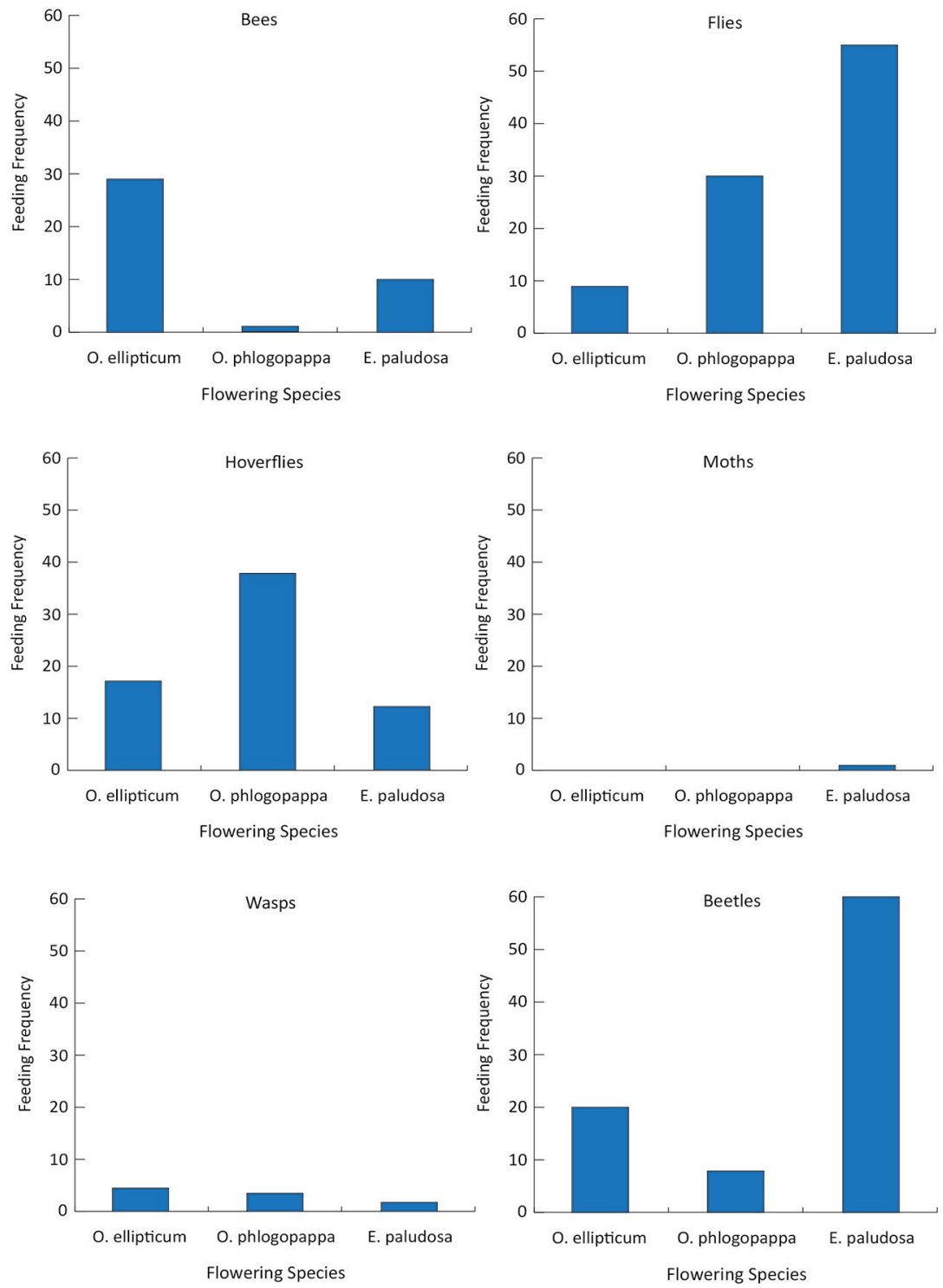

Figure 2: Frequency of feeding by insects for the three focal plant species. Source: Authors' data. 


\section{Discussion}

This project was conducted for just two days and then altered because of weather. The notes here are provided as a summary of what was done.

Despite visible trends towards pollinator selection, no significant difference could be determined overall. Greater time, more varied conditions, surveys of present insect species and control for plant height (e.g. beetles fly less than bees, so may pollinate yellow plants low to the ground but not higher yellow plants, leading to misleading results) could all refine discussion of alpine plant-pollinator relationships.

\section{Acknowledgements}

We thank Micheal Whitehead for his support and advice, and for supporting our decision when the weather changed and we decided to pull the plug on this project.

\section{References}

Costin AB, Gray M, Totterdell CJ, Wimbush DJ (2000) Kosciuszko Alpine Flora, 2nd edn. CSIRO Publishing, Melbourne.

Dafni A, Potts SG (2004) The role of flower inclination, depth, and height in the preferences of a pollinating beetle (Coleoptera: Glaphyridae). Journal of Insect Behaviour 17: 823-34. doi.org/10.1023/ B:JOIR.0000048991.45453.73

Gollan JR, Ashcroft MB, Batley M (2011) Comparison of yellow and white pan traps in surveys of bee fauna in New South Wales, Australia (Hymenoptera: Apoidea: Anthophila). Australian Journal of Entomology 50: 174-8. doi.org/10.1111/j.1440-6055.2010.00797.x

Inouye DW, Pyke GH (1988) Pollination biology in the Snowy Mountains of Australia: Comparisons with montane Colorado, USA. Australian Journal of Ecology 13: 191-210. doi.org/10.1111/j.1442-9993.1988. tb00968.x 
RESEARCHING FUNCTIONAL ECOLOGY IN KOSCIUSZKO NATIONAL PARK

Lord, JM (2008) A test for phylogenetic conservation in plant-pollinator relationships in Australian and New Zealand alpine flora. New Zealand Journal of Botany 46: 367-72. doi.org/10.1080/00288250809509774

Pickering CM, Stock M (2004) Insect colour preference compared to flower colours in the Australian Alps, Nordic Journal of Botany 23: 217-23. doi.org/10.1111/j.1756-1051.2003.tb00384.x 
This text is taken from Researching functional ecology in Kosciuszko National Park, edited by Hannah Zurcher, Chia Ming-Dao, Michael Whitehead and Adrienne Nicotra, published 2017 by ANU eView, The Australian National University, Canberra, Australia. dx.doi.org/10.22459/RFEKNP.11.2017.13 